\title{
Bioactive Phytochemicals from Wild Arbutus unedo L. Berries from Different Locations in Portugal: Quantification of Lipophilic Components
}

\author{
Daniela F. S. Fonseca ${ }^{1}$, Ângelo C. Salvador ${ }^{1,2}$, Sónia A. O. Santos ${ }^{2}$, Carla Vilela ${ }^{2}$, \\ Carmen S. R. Freire ${ }^{2}$, Armando J. D. Silvestre ${ }^{2, *}$ and Sílvia M. Rocha ${ }^{1, *}$
}

1 Organic Chemistry, Natural and Agro-Food Products (QOPNA), Department of Chemistry, University of Aveiro, 3810-193 Aveiro, Portugal; E-Mails: danielafonseca@ua.pt (D.F.S.F.); angelomcsalvador@ua.pt (A.C.S.)

2 Aveiro Institute of Materials (CICECO), Department of Chemistry, University of Aveiro, 3810-193 Aveiro, Portugal; E-Mails: santos.sonia@ua.pt (S.A.O.S.); cvilela@ua.pt (C.V.); cfreire@ua.pt (C.S.R.F.)

* Authors to whom correspondence should be addressed;

E-Mails: armsil@ua.pt (A.J.D.S.); smrocha@ua.pt (S.M.R.);

Tel.: +351-234-370-711 (A.J.D.S.); +351-234-401-524 (S.M.R.);

Fax: +351-234-370-084 (A.J.D.S. \& S.M.R.).

Academic Editor: Maurizio Battino

Received: 24 April 2015 / Accepted: 11 June 2015 / Published: 23 June 2015

\begin{abstract}
The lipophilic composition of wild Arbutus unedo L. berries, collected from six locations in Penacova (center of Portugal), as well as some general chemical parameters, namely total soluble solids, $\mathrm{pH}$, titratable acidity, total phenolic content and antioxidant activity was studied in detail to better understand its potential as a source of bioactive compounds. The chemical composition of the lipophilic extracts, focused on the fatty acids, triterpenoids, sterols, long chain aliphatic alcohols and tocopherols, was investigated by gas chromatography-mass spectrometry (GC-MS) analysis of the dichloromethane extracts. The lipophilic extractives of the ripe A. unedo berries ranged from $0.72 \%$ to $1.66 \%$ ( $w / w$ of dry weight), and consisted mainly of triterpenoids, fatty acids and sterols. Minor amounts of long chain aliphatic alcohols and tocopherols were also identified. Forty-one compounds were identified and among these, ursolic acid, lupeol, $\alpha$-amyrin, linoleic and $\alpha$-linolenic acids, and $\beta$-sitosterol were highlighted as the major components. To the best of our knowledge the current research study provides the most detailed phytochemical
\end{abstract}


repository for the lipophilic composition of $A$. unedo, and offers valuable information for future valuation and exploitation of these berries.

Keywords: Arbutus unedo L.; ripe berries; GC-MS analysis; lipophilic composition; triterpenoids; fatty acids; sterols

\section{Introduction}

Arbutus unedo L. (A. unedo), also known as strawberry tree, is a Mediterranean plant belonging to the Ericaceae family and Vaccionioideae (or Arbutoideae) subfamily, with an extension along the Atlantic coast of Europe [1,2]. A. unedo is an evergreen shrub with spherical berries covered with conical hair-like spikes, soft yellow pulp and an average diameter of $2 \mathrm{~cm}$ [2,3]. A. unedo berries exploitation can be traced back to ancient times where their use in folk medicine is claimed, namely in treatment of kidney diseases, cardiovascular, gastrointestinal, dermatologic and urological disorders $[4,5]$. Nowadays, the market associated to these berries is mainly oriented to the production of alcoholic distillates and also for jellies and jams [6], and are seldom eaten as fresh fruits [7,8].

Understanding the chemical composition of foods, particularly focusing on the phytochemical fingerprinting, has become central to research in order to address the increasing demand for nutraceuticals in foods [9]. The chemical composition of strawberry tree berries regarding the macroand micro-nutrients and phenolic compounds is relatively well known [6-8,10-25]. In the lipophilic fraction, the presence of polyunsaturated fatty acids, namely $\alpha$-linolenic $\left(\mathrm{C} 18: 3^{(\Delta 9,12,15)}\right)$ and linoleic acid $\left(\mathrm{C} 18: 2^{(\Delta 9,12)}\right)$ [12,15,18,24], of triterpenoids, such as lupeol, $\alpha$ - and $\beta$-amyrin, olean-12-en-3 $\beta, 23$-diol, lupenone, amyrone, ursolic aldehyde, $\alpha$-amyrenone, uvaol, and ursolic and oleanolic acids [26,27] and of sterols, such as 5- $\alpha$-cholestane, cholestan-3-one, cholesterol, stigmasterol and stigmast-4-en-3-one [27] has been reported. However, to the best of our knowledge, there is a lack of studies regarding the detailed quantification of these lipophilic components in $A$. unedo berries.

The particular interest in fatty acids, triterpenoids and sterols, results from their recognized benefits in human nutrition and therefore their importance for the valorization of these berries: lipophilic components have shown a wide range of biological activities such as hypocholesterolemic effect, anti-inflammatory, antitumor activities among others [28,29].

In this context, the present study aims to increase the depth of knowledge about the lipophilic fraction (focused on the fatty acids, long chain aliphatic alcohols, triterpenoids, sterols and tocopherols) by GC-MS of wild A. unedo berries lipophilic extracts. In order to establish a more representative lipophilic profile, wild samples harvested from six locations in Penacova (center of Portugal) were evaluated. Moreover, to contribute to a more complete characterization of A. unedo berries, this study also provides baseline information concerning total soluble solids, $\mathrm{pH}$, titratable acidity, total phenolic content and antioxidant activity. 


\section{Results and Discussion}

\subsection{General Chemical Characterization}

The general chemical parameters of the ripe A. unedo berries, namely total soluble solids (TSS), titratable acidity (TA), $\mathrm{pH}$, total phenolic content (TPC), antioxidant activity and water content are displayed in Table 1. The GPS coordinates and the dichloromethane extraction yields are also presented.

In the present study, A. unedo berries revealed water content ranging between $61.13 \%$ in location 3 and $69.80 \%$ in location 5 . These values were comparable to the previously reported for these berries which ranges from $42.78 \%$ to $72.59 \%$ [22,30]. The TSS of $A$. unedo berries ranged from $22.4 \pm 0.3$ to $30.1 \pm 0.8^{\circ}$ Brix. Fruits from location 2 and 3 presented the lowest and the highest values, respectively. The TSS of $A$. unedo berries was similar to previously reported data from Portuguese fruits $\left(\approx 22^{\circ}\right.$ Brix) [20] and from other European origins (16.50-31.68 ${ }^{\circ}$ Brix) [30-32]. The TA of the fruits collected from the six locations was very similar, ranging between $c a .0 .8 \mathrm{~g}$ of malic acid per $100 \mathrm{~g}$ fresh weight in location 4, and ca. $0.9 \mathrm{~g}$ of malic acid per $100 \mathrm{~g}$ fresh weight, in location 6 . TA for Portuguese fruits was assessed for the first time and the results were within the range reported for the fruits harvested out of Portugal (0.4-1.59 g of malic acid per $100 \mathrm{~g}$ fresh weight) [21,30-32]. Similarly to TA, $\mathrm{pH}$ of the Portuguese fruits was evaluated here for the first time and ranged from $2.97 \pm 0.05$ in location 2 , to $3.17 \pm 0.07$ in location 4 . $\mathrm{pH}$ values of the berries under study were lower than the ones already reported for $A$. unedo fruits, ranging between 3.21 and 4.6 [21,22,32]. TPC, expressed as mg gallic acid per $100 \mathrm{~g}$ fresh weight, varied from $1160 \pm 13$ in location 2, to $2222 \pm 35$, in location 6 . TPC in $A$. unedo berries reached higher values than those already published, not only considering Portuguese samples ( $\approx 445-941 \mathrm{mg}$ of gallic acid per $100 \mathrm{~g}$ fresh weight), but also the European ones (590-1973 mg of gallic acid per $100 \mathrm{~g}$ fresh weight) [22,30].

The antioxidant activity of the studied $A$. unedo berries ranged between $0.278 \pm 0.02$, in location 6 , and $0.589 \pm 0.01 \mathrm{mg}$ of extract per $\mathrm{mL} \mathrm{DPPH}$, in location 2. The fruits collected from location 6 presented the lowest $\mathrm{EC}_{50}$ value, revealing the highest radical scavenging activity among the samples and therefore, the highest antioxidant activity. The results obtained were within the range reported in literature for these ripe berries $(0.25-0.79 \mathrm{mg}$ extract per $\mathrm{mL} \mathrm{DPPH})[15,18,33]$.

The comparison between the fruits collected from the six locations in the center of Portugal (Table 1) allowed us to observe a wide variability in the chemical parameters investigated. The differences detected can be attributed to various factors such as year, genetic variability (genetic data are not available, however different morphological characteristics of the berries and leaves may support this idea) and geographic position [17,22]. 
Table 1. Geographical (GPS) coordinates, general chemical characterization and dichloromethane extraction yields of $A$. unedo berries harvested from six locations in Penacova (center of Portugal).

\begin{tabular}{|c|c|c|c|c|c|c|c|c|c|c|}
\hline \multirow{2}{*}{ Location } & \multicolumn{3}{|c|}{ GPS Coordinates } & \multirow{2}{*}{$\begin{array}{c}\text { Moisture } \\
(\%)\end{array}$} & \multirow{2}{*}{$\begin{array}{c}\text { Total Soluble } \\
\text { Solids }^{\text {a }}\end{array}$} & \multirow{2}{*}{$\begin{array}{l}\text { Titratable } \\
\text { Acidity }^{\mathbf{b}}\end{array}$} & \multirow{2}{*}{ pH } & \multirow{2}{*}{$\begin{array}{c}\text { Total Phenolic } \\
\text { Content }^{c}\end{array}$} & \multirow{2}{*}{$\begin{array}{l}\text { Antioxidant } \\
\text { Activity }^{\text {d }}\end{array}$} & \multirow{2}{*}{$\begin{array}{c}\text { Extraction Yield } \\
(\%, w / w) \\
\end{array}$} \\
\hline & Latitude & Longitude & Altitude (m) & & & & & & & \\
\hline 1 & $40^{\circ} 18^{\prime} 22.3^{\prime \prime} \mathrm{N}$ & $8^{\circ} 10^{\prime} 00.5^{\prime \prime} \mathrm{W}$ & 200.76 & 69.80 & $24.4 \pm 0.5$ & $0.89 \pm 0.02$ & $3.08 \pm 0.02$ & $1342 \pm 76$ & $0.469 \pm 0.02$ & 1.66 \\
\hline 2 & $40^{\circ} 17^{\prime} 33.2^{\prime \prime} \mathrm{N}$ & $8^{\circ} 11^{\prime} 52.1^{\prime \prime} \mathrm{W}$ & 125.00 & 62.53 & $22.4 \pm 0.3$ & $0.88 \pm 0.02$ & $2.97 \pm 0.05$ & $1160 \pm 13$ & $0.589 \pm 0.01$ & 1.56 \\
\hline 3 & $40^{\circ} 17^{\prime} 36.7^{\prime \prime} \mathrm{N}$ & $8^{\circ} 11^{\prime} 51.1^{\prime \prime} \mathrm{W}$ & 123.22 & 61.13 & $30.1 \pm 0.8$ & $0.85 \pm 0.09$ & $3.17 \pm 0.04$ & $1185 \pm 18$ & $0.359 \pm 0.03$ & 1.48 \\
\hline 4 & $40^{\circ} 16^{\prime} 53.4^{\prime \prime} \mathrm{N}$ & $8^{\circ} 12^{\prime} 25.8^{\prime \prime} \mathrm{W}$ & 100.00 & 61.87 & $25.7 \pm 0.6$ & $0.81 \pm 0.10$ & $3.17 \pm 0.07$ & $1889 \pm 66$ & $0.356 \pm 0.01$ & 1.58 \\
\hline 5 & $40^{\circ} 16^{\prime} 37.4^{\prime \prime} \mathrm{N}$ & $8^{\circ} 11^{\prime} 57.5^{\prime \prime} \mathrm{W}$ & 75.00 & 67.87 & $28.3 \pm 0.5$ & $0.89 \pm 0.09$ & $3.09 \pm 0.07$ & $2183 \pm 48$ & $0.343 \pm 0.06$ & 1.55 \\
\hline 6 & $40^{\circ} 16^{\prime} 34.7^{\prime \prime} \mathrm{N}$ & $8^{\circ} 11^{\prime} 50.3^{\prime \prime} \mathrm{W}$ & 75.00 & 69.47 & $22.9 \pm 0.2$ & $0.91 \pm 0.02$ & $3.05 \pm 0.07$ & $2222 \pm 35$ & $0.278 \pm 0.02$ & 0.72 \\
\hline
\end{tabular}

${ }^{\mathrm{a}}$ Expressed as ${ }^{\circ}$ Brix; ${ }^{\mathrm{b}}$ Expressed as g of malic acid per $100 \mathrm{~g}$ fresh weight; ${ }^{\mathrm{c}}$ Expressed as mg of gallic acid per $100 \mathrm{~g}$ fresh weight; ${ }^{\mathrm{d}}$ Expressed as EC ${ }_{50}$ : mg of extract per mL DPPH. 


\subsection{Chemical Characterization of the Lipophilic Extractives from A. unedo Berries}

The dichloromethane extraction yields (Table 1) of ripe $A$. unedo fruits ranged between $0.72 \%$ and $1.66 \%$. We observed that the lowest extractive yield, $0.72 \%$, found in sample 6 , is nearly half of the extractive yields obtained for the berries collected from location 1 to 5 . The great discrepancy in the lipidic content observed in $A$. unedo is in agreement with previously reported data concerning other berries, namely mulberries (Morus spp.), which ranged from $0.14 \%$ to $0.40 \%$. These fluctuations may be due to different environmental conditions where the species are grown [34] and also to the genetic diversity of the plants [35]. To the best of our knowledge there are no reports in the literature about lipophilic extractives yields of $A$. unedo fruits. Nevertheless, these lipophilic contents were similar to those found for other berries such as elderberries (Sambucus nigra L.) [36].

The lipophilic fraction of $A$. unedo fruits harvested from six different locations presented similar compositions, either before or after alkaline hydrolysis. Figure 1 shows a typical GC-MS chromatogram of the A. unedo berries dichloromethane derivatized extract after alkaline hydrolysis.

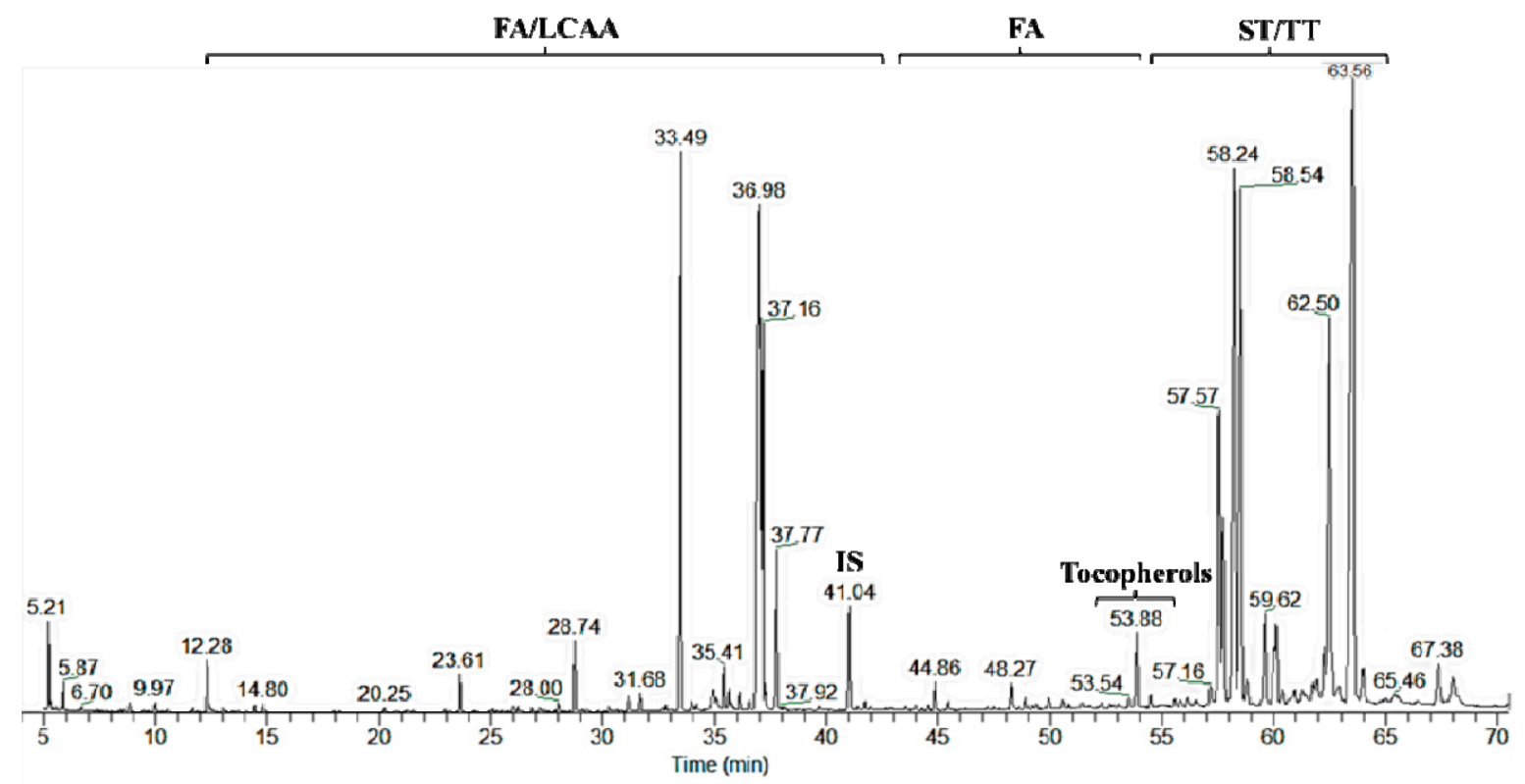

Figure 1. GC-MS chromatogram of the trimethylsilyl (TMS)-derivatized dichloromethane extracts of $A$. unedo berries after alkaline hydrolysis. Abbreviations: FA, fatty acids; LCAA, long chain aliphatic alcohols; IS, internal standard; ST, sterols; TT, triterpenoids.

The GC-MS analysis allowed the identification of 41 compounds belonging to five chemical families, namely triterpenoids, sterols, fatty acids, long chain aliphatic alcohols and tocopherols. The detailed information about the individual components identified, expressed as $\mathrm{mg}$ of compound per $100 \mathrm{~g}$ of fresh berries, before and after alkaline hydrolysis, is summarized in Table 2. Triterpenoids, followed by fatty acids and sterols, were the major families of lipophilic compounds found in fruits from all locations as illustrated in Figure 2 and Table 2. 


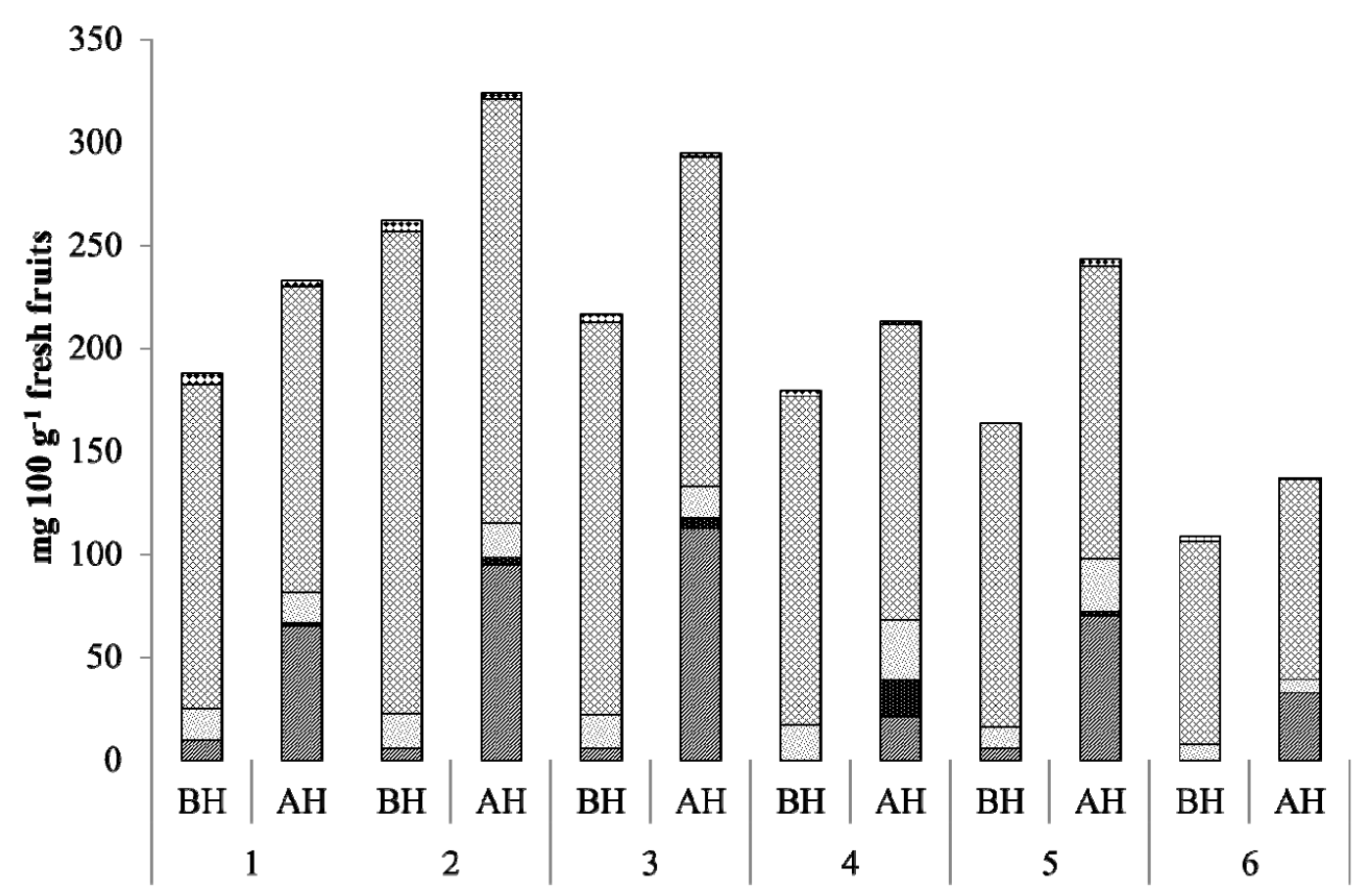

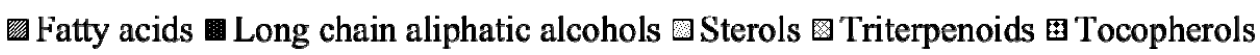

Figure 2. Major families of lipophilic compounds identified in $A$. unedo berries collected from six locations in Penacova (center of Portugal), before (BH) and after (AH) alkaline hydrolysis.

Triterpenoids represented the major family of lipophilic components of $A$. unedo berries (Table 2). This family accounted for up to $90 \%$ of the total amount of detected compounds before hydrolysis and up to $70 \%$ after hydrolysis (mainly due to the strong increment in the amount of fatty acids). The triterpenoids content ranged from 97 and $99 \mathrm{mg}$ per $100 \mathrm{~g}$ of fresh weight after and before hydrolysis, respectively, in location 6, to 206 and $234 \mathrm{mg}$ per $100 \mathrm{~g}$ of fresh weight after and before hydrolysis, respectively, in location 2. Ursolic acid was the major compound representing up to $39 \%$ of all identified compounds before hydrolysis and up to $25 \%$ after hydrolysis.

Other identified triterpenoids included lupeol, oleanolic acid, uvaol, olean-12-en-3 $\beta, 23$-diol, $\alpha$ - and $\beta$-amyrin and lupeol derivatives. All the triterpenoids identified in the present study have been previously described as $A$. unedo fruits lipophilic components [27], but without any quantification The total triterpenoids content of strawberry tree fruits is within the range of 100-240 mg of triterpenoids per $100 \mathrm{~g}$ fresh fruit, a value higher than that reported for other berries such as bilberry (Vaccinium myrtillus L.), which ranges between $c a .75$ and $80 \mathrm{mg}$ triterpenoids per $100 \mathrm{~g}$ fresh fruit [37].

Fatty acids (Table 2) represented the second major group of lipophilic compounds present in A. unedo fruits, corresponding to $1 \%-5 \%$ (1 to $10 \mathrm{mg}$ per $100 \mathrm{~g}$ of fresh weight) of the total amount of detected lipophilic compounds in the dry extract before hydrolysis and between $10 \%$ and $38 \%$ after hydrolysis ( 21 to $112 \mathrm{mg}$ per $100 \mathrm{~g}$ of fresh weight). 
Table 2. Lipophilic composition (expressed as $\mathrm{mg}$ per $100 \mathrm{~g}^{-1}$ fresh weight) of $A$. unedo berries collected from six locations in Penacova (center of Portugal) Portugal, before $(\mathrm{BH})$ and after $(\mathrm{AH})$ alkaline hydrolysis. ${ }^{\text {a }}$

\begin{tabular}{|c|c|c|c|c|c|c|c|c|c|c|c|c|c|}
\hline \multirow{3}{*}{ R.t. (min) } & \multirow{3}{*}{ Compound } & \multicolumn{12}{|c|}{ Locations } \\
\hline & & \multicolumn{2}{|c|}{1} & \multicolumn{2}{|c|}{2} & \multicolumn{2}{|c|}{3} & \multicolumn{2}{|c|}{4} & \multicolumn{2}{|c|}{5} & \multicolumn{2}{|c|}{6} \\
\hline & & BH & AH & BH & $\mathbf{A H}$ & BH & AH & BH & AH & BH & AH & BH & $\mathbf{A H}$ \\
\hline & Fatty Acids & 10 & 75 & 6 & 95 & 5 & 120 & 1 & 21 & 5 & 70 & 1 & 33 \\
\hline & Saturated & 6 & 19 & 3 & 20 & 4 & 28 & $\operatorname{tr}$ & 10 & 5 & 24 & 0 & 14 \\
\hline 8.46 & Hexanoic acid C6:0 & nd & $\operatorname{tr}$ & nd & $\operatorname{tr}$ & nd & $\operatorname{tr}$ & nd & $\operatorname{tr}$ & nd & $\operatorname{tr}$ & nd & $\operatorname{tr}$ \\
\hline 11.68 & Octanoic acid C8:0 & nd & $\operatorname{tr}$ & nd & $\operatorname{tr}$ & nd & $\operatorname{tr}$ & nd & $\operatorname{tr}$ & nd & $\operatorname{tr}$ & nd & $\operatorname{tr}$ \\
\hline 14.87 & Nonanoic acid C9:0 & nd & $\operatorname{tr}$ & nd & $\operatorname{tr}$ & nd & $\operatorname{tr}$ & nd & $\operatorname{tr}$ & nd & $\operatorname{tr}$ & nd & $\operatorname{tr}$ \\
\hline 17.96 & Decanoic acid C10:0 & nd & $\operatorname{tr}$ & nd & $\operatorname{tr}$ & nd & $\operatorname{tr}$ & nd & $\operatorname{tr}$ & nd & $\operatorname{tr}$ & nd & $\operatorname{tr}$ \\
\hline 23.61 & Dodecanoic acid C12:0 & $\operatorname{tr}$ & 1 & $\operatorname{tr}$ & $\operatorname{tr}$ & $\operatorname{tr}$ & $\operatorname{tr}$ & $\operatorname{tr}$ & $\operatorname{tr}$ & $\operatorname{tr}$ & $\operatorname{tr}$ & $\operatorname{tr}$ & $\operatorname{tr}$ \\
\hline 26.94 & Tridecanoic acid C13:0 & nd & $\operatorname{tr}$ & nd & $\operatorname{tr}$ & nd & $\operatorname{tr}$ & nd & $\operatorname{tr}$ & nd & $\operatorname{tr}$ & nd & $\operatorname{tr}$ \\
\hline 28.74 & Tetradecanoic acid C14:0 & nd & 2 & nd & 1 & nd & 2 & nd & 1 & nd & 1 & nd & 2 \\
\hline 31.78 & Pentadecanoic acid C15:0 & nd & $\operatorname{tr}$ & nd & $\operatorname{tr}$ & nd & $\operatorname{tr}$ & nd & $\operatorname{tr}$ & nd & $\operatorname{tr}$ & nd & $\operatorname{tr}$ \\
\hline 33.49 & Hexadecanoic acid C16:0 & 6 & 12 & 3 & 12 & 4 & 23 & nd & 4 & nd & 10 & nd & 9 \\
\hline 35.64 & Heptadecanoic acid C17:0 & nd & $\operatorname{tr}$ & nd & $\operatorname{tr}$ & nd & $\operatorname{tr}$ & nd & 3 & nd & 7 & nd & $\operatorname{tr}$ \\
\hline 37.77 & Octadecanoic acid C18:0 & $\operatorname{tr}$ & 5 & $\operatorname{tr}$ & 8 & $\operatorname{tr}$ & 10 & $\operatorname{tr}$ & 2 & 5 & 4 & $\operatorname{tr}$ & 3 \\
\hline 41.73 & Eicosanoic acid C20:0 & nd & $\operatorname{tr}$ & nd & $\operatorname{tr}$ & nd & $\operatorname{tr}$ & nd & $\operatorname{tr}$ & nd & 1 & nd & $\operatorname{tr}$ \\
\hline 45.45 & Docosanoic acid C22:0 & $\operatorname{tr}$ & $\operatorname{tr}$ & nd & $\operatorname{tr}$ & $\operatorname{tr}$ & $\operatorname{tr}$ & $\operatorname{tr}$ & $\operatorname{tr}$ & $\operatorname{tr}$ & 1 & $\operatorname{tr}$ & $\operatorname{tr}$ \\
\hline 47.08 & Tricosanoic acid C23:0 & nd & $\operatorname{tr}$ & nd & $\operatorname{tr}$ & nd & $\operatorname{tr}$ & nd & $\operatorname{tr}$ & nd & $\operatorname{tr}$ & nd & $\operatorname{tr}$ \\
\hline \multirow[t]{2}{*}{48.91} & Tetracosanoic acid C24:0 & $\operatorname{tr}$ & $\operatorname{tr}$ & $\operatorname{tr}$ & $\operatorname{tr}$ & $\operatorname{tr}$ & $\operatorname{tr}$ & $\operatorname{tr}$ & $\operatorname{tr}$ & $\operatorname{tr}$ & $\operatorname{tr}$ & $\operatorname{tr}$ & $\operatorname{tr}$ \\
\hline & Unsaturated & 4 & 46 & 2 & 75 & 1 & 85 & 1 & 11 & 1 & 45 & 1 & 19 \\
\hline $\begin{array}{l}32.68 \\
32.81\end{array}$ & $\begin{array}{l}\text { Hexadec-9-enoic acid C16:1 }{ }^{(\Delta 9)} \text { isomer } \\
\text { Hexadec-9-enoic acid C16:1 }{ }^{(\Delta 9)} \text { isomer }\end{array}$ & $\operatorname{tr}$ & $\operatorname{tr}$ & $\operatorname{tr}$ & $\operatorname{tr}$ & $\operatorname{tr}$ & $\operatorname{tr}$ & $\operatorname{tr}$ & 1 & $\operatorname{tr}$ & $\operatorname{tr}$ & $\operatorname{tr}$ & 10 \\
\hline 36.98 & $\begin{array}{l}\text { Octadeca-9,12-dienoic acid C18:2 } 2^{(\Delta 9,12)}+ \\
\text { Octadeca-9,12,15-trienoic acid C18:3 } 3^{(\Delta 9,12,15)}\end{array}$ & 4 & 33 & 2 & 75 & 1 & 85 & 1 & 10 & 1 & 45 & 1 & 6 \\
\hline $\begin{array}{l}37.16 \\
37.26\end{array}$ & $\begin{array}{l}\text { Octadec-9-enoic acid C18:1 }{ }^{\left({ }^{(9)}\right)} \text { isomer } \\
\text { Octadec-9-enoic acid C18:1 }{ }^{\left({ }^{(4)}\right)} \text { isomer }\end{array}$ & $\operatorname{tr}$ & 23 & $\operatorname{tr}$ & $\operatorname{tr}$ & $\operatorname{tr}$ & $\operatorname{tr}$ & $\operatorname{tr}$ & $\operatorname{tr}$ & $\operatorname{tr}$ & $\operatorname{tr}$ & $\operatorname{tr}$ & 3 \\
\hline
\end{tabular}


Table 2. Cont.

\begin{tabular}{|c|c|c|c|c|c|c|c|c|c|c|c|c|c|}
\hline \multirow{3}{*}{ R.t. (min) } & \multirow{3}{*}{ Compound } & \multicolumn{12}{|c|}{ Locations } \\
\hline & & \multicolumn{2}{|c|}{1} & \multicolumn{2}{|c|}{2} & \multicolumn{2}{|c|}{3} & \multicolumn{2}{|c|}{4} & \multicolumn{2}{|c|}{5} & \multicolumn{2}{|c|}{6} \\
\hline & & BH & AH & BH & AH & BH & $\mathbf{A H}$ & BH & AH & BH & AH & BH & $\mathbf{A H}$ \\
\hline & Long Chain Aliphatic Alcohols & $\mathbf{0}$ & 2 & $\mathbf{0}$ & 4 & $\mathbf{0}$ & 5 & $\mathbf{0}$ & 17 & $\mathbf{0}$ & 2 & $\mathbf{0}$ & tr \\
\hline 26.84 & Tetradecan-1-ol & nd & $\operatorname{tr}$ & nd & $\operatorname{tr}$ & nd & $\operatorname{tr}$ & nd & 1 & nd & $\operatorname{tr}$ & nd & $\operatorname{tr}$ \\
\hline 31.68 & Hexadecan-1-ol & nd & $\operatorname{tr}$ & nd & $\operatorname{tr}$ & nd & 1 & nd & 9 & nd & 1 & nd & $\operatorname{tr}$ \\
\hline 35.41 & Octadec-9-en-1-ol & nd & 2 & nd & 4 & nd & 4 & nd & 7 & nd & 1 & nd & $\operatorname{tr}$ \\
\hline \multirow[t]{2}{*}{36.12} & Octadecan-1-ol & nd & $\operatorname{tr}$ & nd & $\operatorname{tr}$ & nd & $\operatorname{tr}$ & nd & $\operatorname{tr}$ & nd & $\operatorname{tr}$ & nd & $\operatorname{tr}$ \\
\hline & Sterols & 15 & 15 & 17 & 16 & 16 & 16 & 16 & 30 & 11 & 26 & 7 & 6 \\
\hline 55.09 & Cholestan-3-one & nd & $\operatorname{tr}$ & $\operatorname{tr}$ & $\operatorname{tr}$ & $\operatorname{tr}$ & $\operatorname{tr}$ & $\operatorname{tr}$ & $\operatorname{tr}$ & $\operatorname{tr}$ & $\operatorname{tr}$ & $\operatorname{tr}$ & $\operatorname{tr}$ \\
\hline 55.83 & Campesterol & nd & 1 & nd & 1 & nd & $\operatorname{tr}$ & nd & $\operatorname{tr}$ & nd & 4 & nd & $\operatorname{tr}$ \\
\hline 56.65 & Stigmasterol & $\operatorname{tr}$ & $\operatorname{tr}$ & $\operatorname{tr}$ & $\operatorname{tr}$ & $\operatorname{tr}$ & $\operatorname{tr}$ & $\operatorname{tr}$ & $\operatorname{tr}$ & $\operatorname{tr}$ & $\operatorname{tr}$ & $\operatorname{tr}$ & $\operatorname{tr}$ \\
\hline \multirow[t]{2}{*}{57.75} & Sitosterol & 15 & 14 & 17 & 16 & 16 & 16 & 16 & 30 & 11 & 21 & 7 & 6 \\
\hline & Triterpenoids & 157 & 149 & 234 & 206 & 191 & 160 & 160 & 144 & 147 & 142 & 99 & 97 \\
\hline 57.16 & Amyrin derivative & 2 & $\operatorname{tr}$ & 2 & 2 & 2 & $\operatorname{tr}$ & 2 & 12 & 1 & 2 & 1 & $\operatorname{tr}$ \\
\hline 57.33 & Lupenone & 3 & 2 & 3 & 3 & 4 & 3 & 3 & 3 & 2 & 1 & 1 & 1 \\
\hline 57.57 & $\beta$-Amyrin & 2 & 1 & 1 & 1 & 2 & 1 & 2 & 26 & $\operatorname{tr}$ & 6 & 1 & 13 \\
\hline 58.24 & $\alpha$-Amyrin & 29 & 26 & 36 & 31 & 32 & 28 & 36 & 35 & 24 & 38 & 37 & 50 \\
\hline 58.54 & Lupeol & 35 & 35 & 49 & 44 & 33 & 30 & 31 & 3 & 31 & 43 & 3 & $\operatorname{tr}$ \\
\hline 59.62 & Lupenyl acetate & 5 & 5 & 8 & 7 & 6 & 5 & 1 & 1 & 3 & 3 & 2 & 3 \\
\hline 62.10 & Olean-12-en-3 $\beta, 23$-diol & 3 & 3 & 5 & 5 & 3 & 3 & 3 & 3 & 3 & 3 & 1 & 2 \\
\hline 62.25 & Uvaol & 1 & 2 & 35 & 31 & 26 & 23 & 3 & 4 & 18 & 7 & 1 & 1 \\
\hline 62.50 & Oleanolic acid & 24 & 22 & 2 & 1 & 2 & 2 & 17 & 21 & 1 & 10 & 10 & 8 \\
\hline \multirow[t]{2}{*}{63.56} & Ursolic acid & 54 & 53 & 93 & 81 & 81 & 63 & 62 & 36 & 63 & 28 & 42 & 20 \\
\hline & Tocopherols & 10 & 2 & 6 & 3 & 4 & 2 & 3 & 1 & 1 & 4 & 2 & 1 \\
\hline 53.88 & $\alpha$-Tocopherol & 4 & 1 & 3 & 2 & 1 & 1 & 1 & 1 & 1 & 2 & 1 & $\operatorname{tr}$ \\
\hline \multirow[t]{2}{*}{54.18} & $\gamma$-Tocopherol & 6 & 2 & 3 & 1 & 3 & 1 & 2 & $\operatorname{tr}$ & $\operatorname{tr}$ & 2 & 1 & $\operatorname{tr}$ \\
\hline & Total (mg $100 \mathrm{~g}^{-1}$ fresh fruit) & 192 & 243 & 262 & 324 & 217 & 303 & 179 & 213 & 164 & 243 & 109 & 137 \\
\hline
\end{tabular}

a Abbreviations: nd, not detected; tr, traces. The results are the average of the concordant values obtained for each sample (less than 5\% variation between injections). 
After hydrolysis, the total fatty acids content increased up to 70 times and the content of unsaturated fatty acids was found to be considerably higher than that of saturated fatty acids in all samples, with the exception of location 4. The highest ratio of unsaturated/saturated fatty acids was about 3.6 in location 2 and the lowest was about 1 in location 4. As illustrated in Figure 2 and Table 2, it can be seen that the fatty acid content of the berries harvested from location 4 is the lowest, when compared to the remaining samples. This difference can be attributed to the complex interactions between intrinsic factors, such as the genetic factors and vegetative stage of the plant, and extrinsic factors such as type of soil, microclimatic conditions (level of radiation, temperature, wind exposure and water availability) and geographic position [35].

The identified fatty acids ranged from hexanoic (C6:0) to tetracosanoic acids (C24:0), including six unsaturated structures (cis- and trans-C16:1 and C18:1, C18:2 and C18:3). Hexadecanoic acid (C16:0) was the most abundant saturated fatty acid in A. unedo fruits with the highest content observed in location 3, with $16 \mathrm{mg}$ per $100 \mathrm{~g}$ of fresh weight after hydrolysis. Octadeca-9,12-dienoic ( $\omega-6)$ and octadeca-9,12,15-trienoic ( $\omega$-3) acids were the major unsaturated fatty acids reaching up to $85 \mathrm{mg}$ per $100 \mathrm{~g}$ of fresh weight in location 3 after hydrolysis. These were followed by cis- and trans-octadec-9-enoic acids and cis- and trans-hexadec-9-enoic acids. The compounds identified in the present study have already been reported in $A$. unedo fruits however, only the contents of hexadecanoic, octadec-9-enoic, octadeca-9,12-dienoic and octadeca-9,12,15-trienoic acids were reported [15,18,30]. Previous studies revealed that octadeca-9,12-dienoic and octadeca-9,12,15-trienoic acids accounted for $92.1 \pm 6.6 \mathrm{mg}$ and $83.5 \pm 16.3 \mathrm{mg}$ per $100 \mathrm{~g}$, followed by hexadecanoic and octadec-9-enoic acids which accounted for $50.01 \pm 1.0$ and $39.9 \pm 9.2 \mathrm{mg}$ per $100 \mathrm{~g}$ fresh weight respectively [30]. In this study, the octadeca-9,12-dienoic and octadeca-9,12,15-trienoic acids content represented about $120 \mathrm{mg}$ per $100 \mathrm{~g}$ fresh fruit, about $23 \mathrm{mg}$ of octadec-9-enoic acid and $24 \mathrm{mg}$ of hexadecanoic acid (Table 2). These results were in agreement with previously reported data on $A$. unedo berries: unsaturated fatty acids were predominant over the saturated fatty acids, with octadeca-9,12-dienoic and octadeca-9,12,15-trienoic acids as the major compounds after hydrolysis [15,30].

The sterols found in A. unedo include cholestan-3-one, campesterol, stigmasterol and $\beta$-sitosterol (Table 2). These phytosterols represented up to $9 \%$ of the total extract before hydrolysis and up to $14 \%$ after hydrolysis (6-30 mg per $100 \mathrm{~g}$ of fresh weight). $\beta$-sitosterol was the main component of this family, representing between $82 \%$ and $100 \%$ of total sterols content (6-30 mg per $100 \mathrm{~g}$ of fresh weight). With the exception of campesterol all the sterols identified in the present study have already been reported in the literature as $A$. unedo berries components [27], but their quantification was not reported before. The sterols content of strawberry tree fruits reported here (Table 2) is similar to the values reported for other berries, such as bilberry (Vaccinium myrtillus L.), with ca. 18 and $23 \mathrm{mg}$ sterols per $100 \mathrm{~g}$ fresh fruit [37], and higher than that reported for sea-buckthorn (Hippophae rhamnoides L.) (0.33 to $0.53 \mathrm{mg}$ per $100 \mathrm{~g}$ of fresh weight) [38].

Long-chain aliphatic alcohols were detected in quite low amounts after alkaline hydrolysis, representing about $1 \%-8 \%$ of the total lipophilic extractives of ripe $A$. unedo fruits (ranged from 2 to $17 \mathrm{mg}$ per $100 \mathrm{~g}$ of fresh weight, for locations 2 and 5, and 4, respectively). No aliphatic alcohols have been detected before hydrolysis. Octadec-9-en-1-ol was the most abundant compound identified, representing $43 \%-100 \%$ of the total long-chain aliphatic alcohols. 
Tocopherols ( $\alpha$ - and $\gamma$-tocopherols) were detected as the minor class of compounds in $A$. unedo berries. The highest tocopherol content (10 mg per $100 \mathrm{~g}$ of fresh weight) was found in location 1 , before hydrolysis, and after hydrolysis in location 5 with $4 \mathrm{mg}$ per $100 \mathrm{~g}$ of fresh weight of berries. The content of tocopherols found in strawberry tree fruits was higher than that reported in literature for the same fruits, with $0.023-9.4 \mathrm{mg}$ per $100 \mathrm{~g}$ fresh weight $[7,18]$.

\section{Experimental Section}

\subsection{Chemicals}

Dichloromethane ( $\geq 99 \%$ purity), methanol ( $\geq 99.8 \%$ purity) and sodium hydroxide ( $\geq 97 \%$ purity) were supplied by Fischer Scientific (Pittsburgh, PA, USA). Hydrochloric acid ( $\geq 37 \%$ ) was purchased from Fluka Chemie (Madrid, Spain). Tetracosane (99\% purity), N,O-bis(trimethylsilyl)trifluoroacetamide (99\% purity), trimethylchlorosilane (99\% purity), hexadecanoic acid ( $\geq 99 \%$ purity), nonadecan-1-ol (99\% purity), cholesterol (99\% purity), ursolic acid ( $\geq 90 \%$ purity), oleanolic acid ( $\geq 97 \%$ purity), and betulinic acid ( $\geq 98 \%$ purity) were obtained from Sigma Chemicals Co. (Madrid, Spain). Pyridine ( $\geq 99.5 \%$ purity) was purchased from Panreac (Castellar del Vallès, Spain).

\subsection{Samples}

A. unedo berries were supplied by Medronhalva Lda., from São Pedro de Alva, in Penacova, Portugal. The wild fruits were harvested from 6 locations (Table 1) in order to acquire a representative sampling, reflecting the natural variability of the berries from that region.

A. unedo berries (around $500 \mathrm{~g}$ for each sample) were hand-harvested on-site at a mature stage, in 11 December 2013. The mature stage was established based on the following parameters: total soluble solids (expressed as ${ }^{\circ}$ Brix, which should be at least 16.5 [31]), titratable acidity (should be at least $0.4 \mathrm{~g}$ of malic acid per $100 \mathrm{~g}$ fresh fruit [31]) and also on fruit's colour (homogenous red-scarlet pigmentation). After harvesting, the fruits were refrigerated, transported to the laboratory and stored at $-20{ }^{\circ} \mathrm{C}$ until analysis.

\subsection{General Chemical Characterization}

The total soluble solids content, titratable acidity and $\mathrm{pH}$ determination was performed as described by Ruiz-Rodríguez et al. [22]. The total soluble solids content was determined using a hand-held refractometer (Atago) directly in the fruits pulp. $\mathrm{pH}$ was measured using a Crison micropH 2000 $\mathrm{pH}$-meter over an homogenized sample (obtained from the fruits manually crushed) $1 / 4(w / v)$ in distilled water. TA was determined by titration with $0.1 \mathrm{M} \mathrm{NaOH}$ until $\mathrm{pH}$ of 8.1 was reached and was expressed as $\mathrm{g}$ malic acid per100 $\mathrm{g}$ fresh weight.

Prior to the total phenolic content and the antioxidant activity determination, the samples were prepared accordingly to Santos et al. [39]. A. unedo berries were freeze-dried using a VirTis BenchTop $\mathrm{K}$ (SP Industries, New York, NY, USA), and the water content determined $\left(105^{\circ} \mathrm{C} / 8 \mathrm{~h}\right)$. Nearly $15 \mathrm{~g}$ $( \pm 0.1)$ of each sample were accurately weighed and ground prior to extraction and submitted to a Soxhlet extraction with dichloromethane for $6 \mathrm{~h}$ to remove the lipophilic fraction. The solid residue was suspended (mass/volume 1:100) in a methanol/water/acetic acid mixture, 49.5:49.5:1 at room 
temperature for $24 \mathrm{~h}$ under constant stirring to extract the phenolic compounds. The suspension was then filtered, methanol removed by low-pressure evaporation, and the extract freeze-dried. All extractions were performed in triplicate.

The total phenolic content of the samples was determined by the Folin-Ciocalteu method as described by Singleton [40]. The method is based on the addition of $500 \mu \mathrm{L}$ of distilled water to $125 \mu \mathrm{L}$ of the diluted sample (the previously mentioned extract) and $125 \mu \mathrm{L}$ of Folin-Ciocalteu reagent. The mixture is kept for $5 \mathrm{~min}$ and then $1.25 \mathrm{~mL}$ of $\mathrm{Na}_{2} \mathrm{CO}_{3}\left(75 \mathrm{~g} \cdot \mathrm{L}^{-1}\right)$ and $1 \mathrm{~mL}$ of distilled water are added. The solutions were kept for $30 \mathrm{~min}$ and then the absorbance was measured at $\lambda=760 \mathrm{~nm}$. All the measurements were made in triplicate, using three aliquots of each extract and the average value was calculated in each case. The total phenolic content was calculated as gallic acid equivalents from the calibration curve of gallic acid standard solutions $\left(50-250 \mathrm{mg} \cdot \mathrm{L}^{-1}\right.$; calibration curve: $\left.y=0.0045 x+0.049 ; r^{2}=0.9989\right)$ and expressed as $\mathrm{mg}$ of gallic acid equivalent (GAE) per $100 \mathrm{~g}$ fresh weight [39].

The antioxidant activity was determined by the DPPH method [41]. Briefly, $3.9 \mathrm{~mL}$ of DPPH solution was added to $0.1 \mathrm{~mL}$ of sample containing different concentrations $(0.313,0.625,1.25,2.5$ and $5 \mathrm{mg}$ extract per $\mathrm{mL}$ of solution). The mixture was kept for $30 \mathrm{~min}$ in the dark. The absorbance was measured at $515 \mathrm{~nm}$, in a Perkin Elmer Lambda $35 \mathrm{UV}-$ Vis Spectrometer and compared with a control sample. All measurements were made in triplicate, using three aliquots of each extract and the average value was calculated in each case. The antioxidant activity was expressed as EC50, mg of dry extract that reduces DPPH in 50\% [39]. EC50 was calculated by: (Abs control - Abs sample)/Abs control $\times 100$ and were determined from the plotted graphs of $\mathrm{EC}_{50}$ against the concentration of the extracts.

For all the above reported methods, three independent aliquots of each sample were analysed.

\subsection{Lipophilic Compounds Determination}

\subsubsection{Extraction}

The lipophilic extracts were obtained as aforementioned in Section 3.3, prior to the extraction of the phenolic fraction. To the extraction of the lipophilic fraction, dichloromethane was chosen because it is a fairly specific solvent for lipophilic extractives for analytical purposes [42].

\subsubsection{Alkaline Hydrolysis}

About $20 \mathrm{mg}( \pm 0.1)$ of each lipophilic extract was accurately weighed and dissolved in $10 \mathrm{~mL}$ of $1 \mathrm{M} \mathrm{NaOH}$ in $50 \%$ aqueous methanol. The mixture was heated at $100{ }^{\circ} \mathrm{C}$, under a nitrogen atmosphere, for $1 \mathrm{~h}$. The reaction mixture was cooled, acidified with $1 \mathrm{M} \mathrm{HCl}$ to $\mathrm{pH} \approx 2$, and then extracted three times with dichloromethane, and the solvent was evaporated to dryness [42]. The alkaline hydrolysis reaction was performed to detect indirectly esterified compounds, e.g., triglycerides, steryl esters, etc.

\subsubsection{GC-MS Analysis}

Before GC-MS analysis, nearly $20 \mathrm{mg}( \pm 0.1)$ of each DCM extract solid residue was accurately weighed and converted into trimethylsilyl (TMS) derivatives according to a previously optimized methodology [43]. Briefly, each sample was dissolved in $250 \mu \mathrm{L}$ of pyridine containing $1 \mathrm{mg}$ of 
tetracosane (internal standard), and compounds with hydroxyl and carboxyl groups were converted into trimethylsilyl ethers and esters, respectively, by adding $250 \mu \mathrm{L}$ of $N, O$-bis(trimethylsilyl)trifluoroacetamide and $50 \mu \mathrm{L}$ of trimethylchlorosilane. The mixture was maintained at $70{ }^{\circ} \mathrm{C}$ for $30 \mathrm{~min}$.

GC-MS analyses were performed using a Trace Gas Chromatograph 2000 Series equipped with a Thermo Scientific DSQ II single-quadropole mass spectrometer (Waltham, MA, USA). Separation of compounds was carried out in a DB-1 J\&W capillary column $(30 \mathrm{~m} \times 0.32 \mathrm{~mm}$ inner diameter, $0.25 \mu \mathrm{m}$ film thickness, Agilent Technologies, Santa Clara, CA, USA) using helium as the carrier gas $\left(35 \mathrm{~cm} \cdot \mathrm{s}^{-1}\right)$. The chromatographic conditions were as follows: initial temperature, $80{ }^{\circ} \mathrm{C}$ for $5 \mathrm{~min}$, temperature rate, $4{ }^{\circ} \mathrm{C} \cdot \mathrm{min}^{-1}$ up to $260{ }^{\circ} \mathrm{C}, 2{ }^{\circ} \mathrm{C} \cdot \mathrm{min}^{-1}$ up to $285{ }^{\circ} \mathrm{C}$, then maintained for $10 \mathrm{~min}$; injector temperature, $250{ }^{\circ} \mathrm{C}$; transfer-line temperature, $290{ }^{\circ} \mathrm{C}$, split ratio, 1:50. The mass spectrometer was operated in the electron impact (EI) mode with electron impact energy of $70 \mathrm{eV}$, and data were collected at a rate of $1 \mathrm{scan} \cdot \mathrm{s}^{-1}$ over a range of $\mathrm{m} / z$ 33-700. The ion source was kept at $250{ }^{\circ} \mathrm{C}$. Data acquisition was carried out with the Xcalibur data system (ThermoFinnigan, San Jose, CA, USA).

Chromatographic peaks were identified as TMS derivatives by comparing their mass spectra with the equipment mass spectral library (Wiley-NIST Mass Spectral Library, Oxford, UK, 1999), with literature MS fragmentation data [43-46] and also by injection of standards. For semi-quantitative analysis, GC-MS was calibrated with hexadecanoic acid for fatty acids, nonadecan-1-ol for long chain aliphatic alcohols, cholesterol for phytosterols, ursolic, oleanolic and betulinic acids for the corresponding compounds relative to tetracosane, used as internal standard as described in detail in previous studies $[44,45]$. The respective response factors needed to obtain correct quantification of the peak areas were calculated as the average of four GC-MS runs. For tocopherol the response factor of sterols was used. The compound contents are expressed as mg per $100 \mathrm{~g}$ of fresh weight of fruit. For each extract, two independent aliquots before alkaline hydrolysis, and another two aliquots after alkaline hydrolysis were prepared. Each aliquot was injected in triplicate. The results of Figure 2 and Table 2 are the average of the concordant values obtained for each sample (less than 5\% variation between injections of the same aliquot).

\section{Conclusions}

The present work represents a detailed phytochemical study about the lipophilic fraction from ripe A. unedo berries, being the berries harvested from six locations from Penacova (center of Portugal). Fatty acids, triterpenoids, sterols, long-chain aliphatic alcohols and tocopherols were the main chemical families under study, with triterpenoids as the predominant compounds, followed by fatty acids and sterols. Long-chain aliphatic alcohols and tocopherols were identified as minor components. Among the 41 compounds identified, ursolic acid, lupeol, linoleic and $\alpha$-linolenic acids and $\beta$-sitosterol were the main constituents. To the best of our knowledge, long chain fatty alcohols, as well as campesterol, were reported for the first time as components of strawberry tree berries and a comprehensive quantification of several lipophilic components was accomplished also for the first time. The present study also unveiled the $A$. unedo berries as a source of $\omega-3$ and $\omega-6$ fatty acids, phytosterols and tocopherols, compounds with well-established beneficial effects in human health. This may be useful to value $A$. unedo fruits as sources of valuable phytochemicals and enhance future applications with nutritional, pharmacological or cosmetic purposes. Furthermore, this information can also be relevant 
for the valorization of residues from $A$. unedo alcoholic beverages distillery. A high variability in the lipophilic content of wild $A$. unedo berries collected from the six locations was observed, therefore it will be important to study the effect of ripening, season, genotype, harvesting and processing in order to understand the profile of variation of the lipophilic composition of $A$. unedo berries. Finally, the full understanding of these berries nutraceutical potential also require a systematic analysis of other fractions as for example phenolic compounds, which will be reported soon.

\section{Acknowledgments}

Funding is acknowledged from the European Regional Development Fund (FEDER) through the Competitive Factors Thematic Operational Program (COMPETE) and from the Foundation for Science and Technology (FCT), Portugal, for funding the Research Units QOPNA-Organic Chemistry, Natural and Agro-Food Products (Research Unit 62/94 QOPNA, under projects PEst-C/QUI/UI0062/2013 and FCOMP-01-0124-FEDER-037296), and CICECO-Aveiro Institute of Materials (UID/CTM/50011/2013). FCT/MCTES (Portugal) is also acknowledged for the doctoral grant to Ângelo C. Salvador (SFRH/BD/73778/2010), the postdoctoral grants to Sónia A. O. Santos (SFRH/BPD/84226/2012) and Carla Vilela (SFRH/BPD/84168/2012), and for a contract under Investigador FCT 2012 to Carmen S. R. Freire (IF/01407/2012). Authors also thank Medronhalva, Lda for supplying the $A$. unedo berries.

\section{Author Contributions}

All co-authors have contributed to this paper. Daniela F. S. Fonseca performed the experiments, analysed the data and wrote the article. Ângelo C. Salvador contributed to the discussion of results and writing of the manuscript. Sónia A. O. Santos, Carla Vilela and Carmen S. R. Freire participated in the analysis of the GC-MS samples and on the revision of the manuscript. Armando J. D. Silvestre and Sílvia M. Rocha designed and supervised the study, contributed also to the discussion of the results, writing and revision of the manuscript.

\section{Conflicts of Interest}

The authors declare no conflict of interest.

\section{References}

1. Torres, J.A.; Valle, F.; Pinto, C.; García-Fuentes, A.; Salazar, C.; Cano, E. Arbutus unedo L. communities in southern Iberian Peninsula mountains. Plant Ecol. 2002, 160, 207-223.

2. Kim, T.L. Edible Medicinal and Non-Medicinal Plants; Springer: New York, NY, USA, 2012; pp. 444-451.

3. Sealy, J.R.; Webb, D.A. Arbutus unedo L. J. Ecol. 1950, 38, 223-236.

4. Leonti, M.; Casu, L.; Sanna, F.; Bonsignore, L. A comparison of medicinal plant use in Sardinia and Sicily—De Materia Medica revisited? J. Ethnopharmacol. 2009, 121, 255-267. 
5. El-Hilaly, J.; Hmammouchi, M.; Lyoussi, B. Ethnobotanical studies and economic evaluation of medicinal plants in Taounate province (Northern Morocco). J. Ethnopharmacol. 2003, 86, 149-158.

6. Pawlowska, A.M.; de Leo, M.; Braca, A. Phenolics of Arbutus unedo L. (Ericaceae) fruits: Identification of anthocyanins and gallic acid derivatives. J. Agric. Food Chem. 2006, 54, 10234-10238.

7. Pallauf, K.; Rivas-Gonzalo, J.C.; del Castillo, M.D.; Cano, M.P.; de Pascual-Teresa, S. Characterization of the antioxidant composition of strawberry tree (Arbutus unedo L.) fruits. J. Food Compos. Anal. 2008, 21, 273-281.

8. Alarcão-E-Silva, M.L.C.M.M.; Leitão, A.E.B.; Azinheira, H.G.; Leitão, M.C.A. The arbutus berry: Studies on its color and chemical characteristics at two mature stages. J. Food Compos. Anal. 2001, $14,27-35$.

9. Nöthlings, U.; Schulze, M.B.; Weikert, C.; Boeing, H.; van der Schouw, Y.T.; Bamia, C.; Benetou, V.; Lagiou, P.; Krogh, V.; Beulens, J.W.J. Intake of vegetables, legumes, and fruit, and risk for all-cause, cardiovascular, and cancer mortality in a European diabetic population. $J$. Nutr. 2008, 138, 775-781.

10. Tavares, L.; Fortalezas, S.; Carrilho, C.; McDougall, G.J.; Stewart, D.; Ferreira, R.B.; Santos, C.N. Antioxidant and antiproliferative properties of strawberry tree tissues. J. Berry Res. 2010, 1, 3-12.

11. Fortalezas, S.; Tavares, L.; Pimpão, R.; Tyagi, M.; Pontes, V.; Alves, P.M.; McDougall, G.; Stewart, D.; Ferreira, R.B.; Santos, C.N. Antioxidant properties and neuroprotective capacity of strawberry tree fruit (Arbutus unedo). Nutrients 2010, 2, 214-229.

12. Miguel, M.G.; Faleiro, M.L.; Guerreiro, A.C.; Antunes, M.D. Arbutus unedo L.: Chemical and biological properties. Molecules 2014, 19, 15799-15823.

13. Guimarães, R.; Barros, L.; Dueñas, M.; Carvalho, A.M.; Queiroz, M.J.R.P.; Santos-Buelga, C.; Ferreira, I.C.F.R. Characterisation of phenolic compounds in wild fruits from Northeastern Portugal. Food Chem. 2013, 141, 3721-3730.

14. Şeker, M.; Toplu, C. Determination and comparison of chemical characteristics of Arbutus unedo L. and Arbutus andrachnae L. (family Ericaceae) fruits. J. Med. Food 2010, 13, 1013-1018.

15. Oliveira, I.; Baptista, P.; Malheiro, R.; Casal, S.; Bento, A.; Pereira, J.A. Influence of strawberry tree (Arbutus unedo L.) fruit ripening stage on chemical composition and antioxidant activity. Food Res. Int. 2011, 44, 1401-1407.

16. Carcache-Blanco, E.J.; Cuendet, M.; Park, E.J.; Su, B.-N.; Rivero-Cruz, J.F.; Farnsworth, N.R.; Pezzuto, J.M.; Douglas Kinghorn, A. Potential cancer chemopreventive agents from Arbutus unedo. Nat. Prod. Res. 2006, 20, 327-334.

17. Maleš, Ž.; Plazibat, M.; Bilušić Vundać, V.; Žuntar, I. Qualitative and quantitative analysis of flavonoids of the strawberry tree-Arbutus unedo L. (Ericaceae). Acta Pharm. 2006, 56, 245-250.

18. Barros, L.; Carvalho, A.M.; Morais, J.S.; Ferreira, I.C.F.R. Strawberry-tree, blackthorn and rose fruits: Detailed characterisation in nutrients and phytochemicals with antioxidant properties. Food Chem. 2010, 120, 247-254. 
19. Ayaz, F.A.; Kucukislamoglu, M.; Reunanen, M. Sugar, non-volatile and phenolic acids composition of strawberry tree (Arbutus unedo L. var. Ellipsoidea) fruits. J. Food Compos. Anal. 2000, 13, 171-177.

20. Guerreiro, A.C.; Gago, C.M.L.; Miguel, M.G.C.; Antunes, M.D.C. The effect of temperature and film covers on the storage ability of Arbutus unedo L. fresh fruit. Sci. Hortic. 2013, 159, 96-102.

21. Özcan, M.M.; Hacıseferoğulları, H. The strawberry (Arbutus unedo L.) fruits: Chemical composition, physical properties and mineral contents. J. Food Eng. 2007, 78, 1022-1028.

22. Ruiz-Rodríguez, B.-M.; Morales, P.; Fernández-Ruiz, V.; Sánchez-Mata, M.-C.; Cámara, M.; Díez-Marqués, C.; Pardo-de-Santayana, M.; Molina, M.; Tardío, J. Valorization of wild strawberry-tree fruits (Arbutus unedo L.) through nutritional assessment and natural production data. Food Res. Int. 2011, 44, 1244-1253.

23. Ruiz-Rodriguez, B.M.; Sánchez-Moreno, C.; de Ancos, B.; Cortes, M.D.; Fernández Ruíz, V.; Camara, M.; Tardío, J. Wild Arbutus unedo L. and Rubus ulmifolius Schott fruits are underutilized sources of valuable bioactive compounds with antioxidant capacity. Friuts 2014, 69, 435-448.

24. Morales, P.; Ferreira, I.C.F.R.; Carvalho, A.M.; Fernández-Ruiz, V.; Sánchez-Mata, M.C.; Cámara, M.; Morales, R.; Tardío, J. Wild edible fruits as a potential source of phytochemicals with capacity to inhibit lipid peroxidation. Eur. J. Lipid Sci. Technol. 2013, 115, 176-185.

25. Oliveira, I.; Baptista, P.; Bento, A.; Pereira, J.A. Arbutus unedo L. and its benefits on human health. J. Food Nutr. Res. 2011, 50, 73-85.

26. Gaspar, E.M.S.M.; das Neves, H.J.C.; Noronha, J.P. Application of HPLC-PBMS to the identification of unknown components in a triterpenoid fraction of Arbutus unedo fruits. J. High Resolut. Chromatogr. 1997, 20, 417-420.

27. Noronha, J.P. Metabolitos Secundários do fruto de Arbutus unedo L. (Medronho). Ph.D. Thesis, Universidade Nova de Lisboa, Lisbon, Portugal, 2001; p. 301.

28. Marinangeli, C.P.F.; Varady, K.A.; Jones, P.J.H. Plant sterols combined with exercise for the treatment of hypercholesterolemia: Overview of independent and synergistic mechanisms of action. J. Nutr. Biochem. 2006, 17, 217-224.

29. Domingues, M.A.R.; Guerra, A.R.; Duarte, M.; Freire, C.S.R.; Neto, C.P.; Silva, C.M.S.; Silvestre, A.J.D. Bioactive triterpenic acids: From agroforestry biomass residues to promising therapeutic tools. Mini Rev. Org. Chem. 2014, 11, 382-399.

30. Vidrih, R.; Hribar, J.; Prgomet, Ž.; Poklar Ulrih, N. The physico-chemical properties of strawberry tree (Arbutus unedo L.) fruits. Croat. J. Food Sci. Technol. 2013, 5, 29-33.

31. Sulusoglu, M.; Cavusoglu, A.; Erkal, S. Arbutus unedo L. (Strawberry tree) selection in Turkey Samanli mountain locations. J. Med. Plants Res. 2011, 5, 3545-3551.

32. Celikel, G.; Demirsoy, L.; Demirsoy, H. The strawberry tree (Arbutus unedo L.) selection in Turkey. Sci. Hortic. 2008, 118, 115-119.

33. Mendes, L.; de Freitas, V.; Baptista, P.; Carvalho, M. Comparative antihemolytic and radical scavenging activities of strawberry tree (Arbutus unedo L.) leaf and fruit. Food Chem. Toxicol. 2011, 49, 2285-2291.

34. Jiang, Y.; Nie, W.-J. Chemical properties in fruits of mulberry species from the Xinjiang province of China. Food Chem. 2015, 174, 460-466. 
35. Flück, H. Intrinsic and extrinsic factors affecting the production of secondary plant products. In Chemical Plant Taxonomy; Swain, T.B., Ed.; Academic Press: London, UK, 1963; pp. 167-186.

36. Salvador, Â.C.; Rocha, S.M.; Silvestre, A.J.D. Lipophilic phytochemicals from elderberries (Sambucus nigra L.): Influence of ripening, cultivar and season. Ind. Crops Prod. 2015, 71, 15-23.

37. Szakiel, A.; Pączkowski, C.; Huttunen, S. Triterpenoid content of berries and leaves of bilberry Vaccinium myrtillus from Finland and Poland. J. Agric. Food Chem. 2012, 60, 11839-11849.

38. Yang, B.; Karlsson, R.M.; Oksman, P.H.; Kallio, H.P. Phytosterols in sea buckthorn (Hippophae rhamnoides L.) berries: Identification and effects of different origins and harvesting times. J. Agric. Food Chem. 2001, 49, 5620-5629.

39. Santos, S.A.O.; Freire, C.S.R.; Domingues, M.R.M.; Silvestre, A.J.D.; Neto, C.P. Characterization of phenolic components in polar extracts of Eucalyptus globulus Labill. Bark by high-performance liquid chromatography-mass spectrometry. J. Agric. Food Chem. 2011, 59, 9386-9393.

40. Rossi, V.L. Colorimetry of total phenolics with phosphomolybdic-phosphotungstic acid reagents. Am. J. Enol. Vitic. 1965, 16, 144-158.

41. Villano, D.; Fernández-Pachón, M.S.; Moyá, M.L.; Troncoso, A.M.; García-Parrilla, M.C. Radical scavenging ability of polyphenolic compounds towards DPPH free radical. Talanta 2007, 71, $230-235$.

42. Freire, C.S.R.; Silvestre, A.J.D.; Neto, C.P. Identification of new hydroxy fatty acids and ferulic acid esters in the wood of Eucalyptus globulus. Holzforschung 2002, 56, 143-149.

43. Domingues, R.M.A.; Sousa, G.D.A.; Silva, C.M.; Freire, C.S.R.; Silvestre, A.J.D.; Neto, C.P. High value triterpenic compounds from the outer barks of several Eucalyptus species cultivated in Brazil and in Portugal. Ind. Crops Prod. 2011, 33, 158-164.

44. Vilela, C.; Santos, S.A.O.; Villaverde, J.J.; Oliveira, L.; Nunes, A.; Cordeiro, N.; Freire, C.S.R.; Silvestre, A.J.D. Lipophilic phytochemicals from banana fruits of several Musa species. Food Chem. 2014, 162, 247-252.

45. Vilela, C.; Santos, S.A.O.; Oliveira, L.; Camacho, J.F.; Cordeiro, N.; Freire, C.S.R.; Silvestre, A.J.D. The ripe pulp of Mangifera indica L.: A rich source of phytosterols and other lipophilic phytochemicals. Food Res. Int. 2013, 54, 1535-1540.

46. Ramos, P.A.B.; Guerra, A.R.; Guerreiro, O.; Freire, C.S.R.; Silva, A.M.S.; Duarte, M.F.; Silvestre, A.J.D. Lipophilic extracts of Cynara cardunculus L. var. altilis (DC): A source of valuable bioactive terpenic compounds. J. Agric. Food Chem. 2013, 61, 8420-8429.

(C) 2015 by the authors; licensee MDPI, Basel, Switzerland. This article is an open access article distributed under the terms and conditions of the Creative Commons Attribution license (http://creativecommons.org/licenses/by/4.0/). 